\title{
Determinants of chronic otitis media with effusion in preschool children: a case-control study
}

\author{
Rebecca E. Walker ${ }^{1 *}$, Jim Bartley², David Flint ${ }^{2}$, John M. D. Thompson ${ }^{1}$ and Edwin A. Mitchell ${ }^{1}$
}

\begin{abstract}
Background: Chronic otitis media with effusion (COME) is a prevalent upper airway infection resulting in hearing loss. The aim of this research was to determine risk factors for COME in preschool children.

Methods: A case-control design was conducted in Auckland, New Zealand from May 2011 until November 2013. The cases were children aged 3 and 4 years referred for tympanostomy tube placement due to a diagnosis of COME $(n=178)$. The controls were a random sample of healthy children aged 3 and 4 years from primary care practices $(n=209)$. The children's guardians completed an interviewer-administered questionnaire that covered topics including socio-demographic information, pregnancy and birth, infant feeding practices, home environment, and respiratory health. In addition, skin prick tests for atopy were performed. Odds ratios (OR) estimating the risk of COME independently associated with the exposures were calculated using a logistic regression model.
\end{abstract}

Results: Children with COME frequently had nasal obstruction (OR: 4.38 [95\% Cl: 2.37-8.28]), always snored (OR: 3.64 [95\% Cl: 1.51-9.15]) or often snored (OR: 2.45 [95\% Cl: 1.04-5.96]), spent more hours per week in daycare (OR per hour/week: 1.03 [95\% Cl: 1.00-1.05]), had frequent colds (OR: 2.67 [95\% Cl: 1.59-4.53]), had siblings who had undergone tympanostomy tube placement (OR: 2.68 [95\% Cl: 1.22-6.02]), underwent long labour (OR: 2.59 [95\% Cl: 1.03-6.79]), and had early introduction of cow's milk (OR: 1.76 [95\% Cl: 1.05-2.97]). Asian ethnicity (OR: 0.20 [95\% Cl: 0.07-0.53]) and having older siblings (OR: 0.54 [95\% Cl: 0.31-0.93]) were inversely associated with COME.

Conclusion: COME in preschool children was associated with pathogen exposure, respiratory infection, and nasal obstruction. Strategies to prevent pathogen transmission warrant investigation. The novel findings of long labour and early cow's milk introduction require replication in future studies.

Keywords: Otitis media with effusion, Risk factors, Upper respiratory tract infections, Nasal obstruction, Snoring, Cow's milk, Long labour, Biofilms

\section{Background}

Otitis media with effusion (OME) is a childhood condition where fluid gathers behind the tympanic membrane. OME is a common reason for doctors' visits, antibiotic use and surgery [1]. Chronic otitis media with effusion (COME), defined as effusion lasting 3 or more months, causes hearing loss that may lead to learning delays and behavioural problems [2].

\footnotetext{
* Correspondence: r.walker@auckland.ac.nz

'Department of Paediatrics: Child and Youth Health, The University of

Auckland, Private Bag 92019, Auckland 1142, New Zealand

Full list of author information is available at the end of the article
}

COME is caused by bacteria and viruses entering the middle ear from the upper respiratory tract, leading to a chronic inflammatory response. COME chronicity may be explained by the formation of biofilms in the middle ear [3]. Biofilms are sessile communities of microorganisms that can evade the host's immune system and are often resistant to antibiotic treatment [1]. Risk factors associated with COME include young age, ethnicity, family history, breastfeeding practices, exposure to other children, and upper respiratory infection (URI) [4]. Acute otitis media (AOM) and OME often follow each other, and can be viewed as aspects of a disease continuum. 
While many risk factors for COME have been reported, there is a lack of recent research in which a wide range of potential determinants and confounders are considered together. The aim of the study was to examine a comprehensive array of variables, including prenatal and perinatal factors for which research is lacking [4], to identify risk factors that are independently associated with COME.

\section{Methods}

\section{Study design}

A case-control study of children aged 3 and 4 years was conducted, to compare children with COME to healthy children.

\section{Setting}

Recruitment and data collection were conducted between May 2011 and November 2013. Subjects were assessed in interview rooms at Waitakere Hospital or North Shore Hospital, in the Waitemata District Health Board (WDHB) catchment area in Auckland. WDHB is the largest of 20 district health boards in New Zealand (NZ), with a population of approximately 560,000 people, and the third most affluent. Its population consists of 10\% Maori, 7\% Pacific Island, and 19\% Asian people, with the remaining $64 \%$ being European or Other ethnicities [5]. Children in NZ have free hospital care and primary care practice visits.

\section{Participants}

Cases were children aged 3 or 4 years referred for tympanostomy tube placement (TTP) at Waitakere Hospital, who had a recent medical history of COME and/or signs of COME confirmed by an otorhinolaryngologist during surgery.

Controls were selected at random from children enrolled in primary care practices in proportion to the number and sex of children those practices had referred to Waitakere Hospital for TTP in 2010. This approach was designed to recruit controls from the same population that cases were referred from, to mitigate against selection bias. Eligible controls were aged 3 or 4 years, had no medical history of TTP, no episodes of OME lasting longer than one month in the past year, and never had OME lasting longer than three months.

Cases and controls were excluded if they had craniofacial abnormalities including Down syndrome or cleft palate, or immunodeficiency, as risk factors for COME in children with these conditions may not be generalizable.

\section{Variables}

An interviewer administered a questionnaire to obtain information regarding socio-demographic factors, pregnancy, feeding practices, allergy, nasal symptoms, and childcare environment. The interviewer was blind to whether the participant was a case or control. Recall misclassification and bias was mitigated by using a standardized questionnaire including validated questions where available.

Respondents could provide multiple ethnicities, which were coded as a single ethnicity using the "prioritized output" method from the NZ Ministry of Health ethnicity data protocol [6]. The ethnicity categories were Maori, Pacific Island, Asian, European, and Other. European and Other ethnicity were grouped into a single European/Other category for analysis due to the small number of subjects of Other ethnicity. Residential address was used to assign NZ Deprivation Index (NZDep) ratings. NZDep is a validated proxy measure of socioeconomic status (SES) ranging from 1 (least deprived) to 10 (most deprived) [7]. Crowding was assessed by number of people per bedroom. Long labour was defined as total length of labour (stage 1 and 2) lasting for $21 \mathrm{~h}$ or longer in first-born children or otherwise lasting 14 or more hours. These cutoffs were based on the top $5^{\text {th }}$ percentile of labour length in our control subjects. Mode of delivery was categorized as unassisted (normal vaginal delivery), elective Caesarean section, emergency Caesarean section, or forceps/vacuum delivery. Reflux in infancy was defined as bringing up milk and crying in pain after feeding. Colic in infancy was defined as prolonged crying, reddened face, tight body, and bringing up knees. Time of first exposure to cow's milk (not including formula or foods containing cow's milk) was dichotomized around the median time in the controls, which was 13 months. Allergic symptoms were assessed using questions from the ISAAC questionnaire (http://isaac.auckland.ac.nz). Allergic rhinoconjunctivitis was defined as sneezing, or a runny, or blocked nose, combined with itchy-watery eyes, in the absence of a cold or flu.

The child's height and weight were measured, their temperature taken using an ear thermometer, pneumatic otoscopy and tympanometry were performed, and skin prick tests for house dust mite, cat pelt, dog, mold, birch tree and grass mix were administered following the Australasian Society of Clinical Immunology and Allergy protocol [8].

Other factors analyzed included maternal age, smoking during pregnancy, induced labour, small for gestational age (bottom $10 \%$ of birth weight adjusted for gestational age, parity, sex, and ethnicity) [9], season of birth, pacifier use, age of solid food introduction, maternal and child supplement use, and body mass index (BMI) Zscore (adjusted for age and sex) [10].

\section{Statistical methods}

To detect an odds ratio of 2 at the 5\% level and $80 \%$ power, assuming an exposure frequency of at least $20 \%$ 
in the controls, a sample size of 173 cases and 173 controls is required.

Statistical analysis was conducted using JMP 12, SAS Institute Inc., Cary, NC, 1989-2015. Categorical variables were analyzed using a chi-squared test and continuous variables were analyzed using a Student $t$-test. Variables with a $P$ value $\leq .1$ were entered into a logistic regression model. Age in months, the child's sex, and NZDep were retained in the model as potential confounders. The model was reduced by excluding the least significant variable with $P>.05$, in a stepwise manner until all variables in the model remained significant at the $5 \%$ level. This was done to maximize sample size, due to missing data for some variables. Sensitivity analyses were conducted by adding each removed variable back into the final model to ensure that they remained non-significant and did not impact the variables in the model.

\section{Results}

Of 259 potential cases identified, 18 were excluded due to surgery being cancelled or postponed, 35 due to not having COME, and 6 due to Down syndrome, cranial-facial abnormalities, or immunodeficiency. Of 200 cases confirmed eligible, 178 (89\%) were enrolled. Of 517 potential controls identified, 27 were no longer in the study area, 47 were no longer in the age range, and 5 had Down syndrome, cranial-facial abnormalities or immunodeficiencies.
A history of COME was found in 66 potential controls, 44 had TTP, 16 could not be contacted, and we were advised not to contact 9 subjects by their primary care practices. Of 303 controls confirmed eligible, 209 (69\%) were enrolled (Fig. 1).

The mean age of the cases was 47.8 months [standard deviation $(\mathrm{SD})=6.79]$, significantly younger than the controls who had a mean age of 49.3 months [SD $=6.67$ ] $(P=.04)$. Of the cases, $62 \%$ were male compared to $58 \%$ of controls $(P=.42)$. Mean NZDep in the cases was 5.5 $[\mathrm{SD}=2.66]$, higher (i.e. more deprived) than the controls who had a mean of $4.8[\mathrm{SD}=2.65](P=.01)$.

Variables with $P$ values over .1 univariably that were not analyzed further were: induced labour, small for gestational age, season of birth, pacifier use, age of solid food introduction, maternal and child supplement use, positive skin prick test, eczema, BMI, and crowding.

Upright bottle-feeding was excluded from further analysis because children with COME are recommended to be bottle-fed upright in NZ [11]. Age at first episode of $\mathrm{AOM}$ and age of first starting antibiotics were excluded because AOM is part of the same disease continuum as COME and antibiotics are frequently prescribed for children with OM.

Variables with $P$ values $\leq .1$ univariably (Table 1 ) were analyzed using logistic regression. Those with $P$ values over .05 in the stepwise model that were not entered into the final model were: maternal smoking during

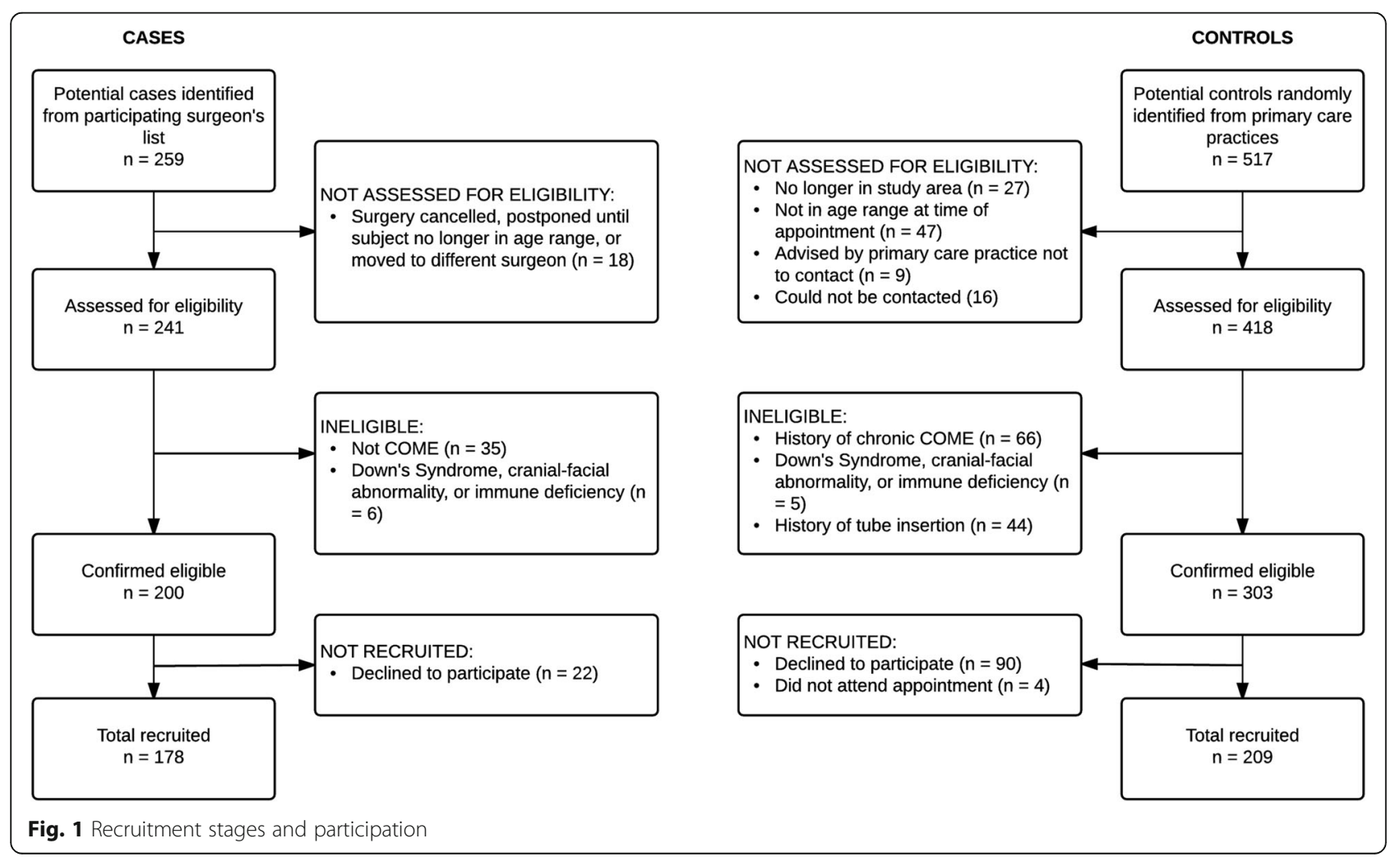


Table 1 Variables with $P$ value of .1 or under in univariable analysis

\begin{tabular}{|c|c|c|c|c|}
\hline Variable & COME $n(\%)$ & Controls $n(\%)$ & $\mathrm{OR}(\mathrm{Cl})$ & $P$ value \\
\hline Ethnicity & & & & $<.001$ \\
\hline European/Other & $102(57.3)$ & $112(53.6)$ & 1.00 & \\
\hline Asian & $7(3.9)$ & $33(15.8)$ & $0.23(0.09,0.52)$ & \\
\hline Maori & $47(26.4)$ & 38 (18.2) & $1.36(0.82,2.26)$ & \\
\hline Pacific Island & $22(12.4)$ & $26(12.4)$ & $0.93(0.49,1.74)$ & \\
\hline Smoking & & & & .006 \\
\hline Neither smoke & $109(61.2)$ & $161(77)$ & 1.00 & \\
\hline Mother smokes & $15(8.4)$ & $12(5.7)$ & $1.05(0.83,4.17)$ & \\
\hline Father smokes & $19(10.7)$ & $16(7.7)$ & $1.75(0.86,3.60)$ & \\
\hline Both smoke & $35(19.7)$ & $20(9.6)$ & $2.58(1.43,4.78)$ & \\
\hline Long labour & & & & .01 \\
\hline No & $153(87.4)$ & $198(94.7)$ & 1.00 & \\
\hline Yes & $22(12.6)$ & $11(5.2)$ & $2.59(1.22,5.50)$ & \\
\hline Maternal smoking during pregnancy & & & & .07 \\
\hline No & $136(76.4)$ & $174(83.7)$ & 1.00 & \\
\hline Yes & $42(23.6)$ & $34(16.3)$ & $1.58(0.95,2.62)$ & \\
\hline Mode of delivery & & & & .06 \\
\hline Unassisted & $102(57.3)$ & $128(61.2)$ & 1.00 & \\
\hline C sect - elective & $15(8.4)$ & $31(14.8)$ & $0.61(0.31,1.18)$ & \\
\hline C sect - emergency & $38(21.3)$ & $30(14.4)$ & $1.61(0.93,2.78)$ & \\
\hline Forceps or vacuum & $23(12.9)$ & $20(9.6)$ & $1.46(0.76,2.82)$ & \\
\hline Breastfed duration (months) & 178 & 208 & $0.96(0.93,0.99)$ & .003 \\
\hline Formula & & & & .006 \\
\hline No & $29(16.3)$ & $58(27.9)$ & 1.00 & \\
\hline Yes & $149(83.7)$ & $150(72.1)$ & $1.99(1.20,3.28)$ & \\
\hline Cow's milk start $<13$ months of age & & & & .009 \\
\hline No & $71(39.9)$ & $111(53.1)$ & 1.00 & \\
\hline Yes & $107(60.1)$ & $98(46.9)$ & $1.71(1.14,2.56)$ & \\
\hline Colic & & & & $<.001$ \\
\hline Never & $54(30.3)$ & $88(42.3)$ & 1.00 & \\
\hline Seldom & $67(37.6)$ & $77(37)$ & $1.42(0.89,2.28)$ & \\
\hline Often & $21(11.8)$ & $28(13.5)$ & $1.22(0.63,2.36)$ & \\
\hline Always & $36(20.2)$ & $15(7.2)$ & $3.91(1.99,7.99)$ & \\
\hline Reflux & & & & .005 \\
\hline Never & $110(61.8)$ & $150(72.1)$ & 1.00 & \\
\hline Seldom & $31(17.4)$ & 39 (18.8) & $1.08(0.63,1.84)$ & \\
\hline Always and often & $37(20.8)$ & $19(9.1)$ & $2.66(1.47,4.95)$ & \\
\hline Probiotic use in last 12 months & & & & .04 \\
\hline No & $153(86.4)$ & $193(92.8)$ & 1.00 & \\
\hline Yes & 24 (13.6) & $15(7.2)$ & $2.02(1.02,3.98)$ & \\
\hline Vitamin C use in last year & & & & .07 \\
\hline No & $137(77.4)$ & $144(69.2)$ & 1.00 & \\
\hline Yes & $40(22.6)$ & $64(30.8)$ & $0.66(0.42,1.04)$ & \\
\hline
\end{tabular}


Table 1 Variables with $P$ value of .1 or under in univariable analysis (Continued)

\begin{tabular}{|c|c|c|c|c|}
\hline Allergic rhinoconjunctivitis in last 12 months & & & & .01 \\
\hline No & $148(83.1)$ & $191(91.4)$ & 1.00 & \\
\hline Yes & $30(16.9)$ & $18(8.6)$ & $2.15(1.15,4.01)$ & \\
\hline Wheeze in last 12 months & & & & .007 \\
\hline No & $99(55.6)$ & $144(68.9)$ & 1.00 & \\
\hline Yes & $79(44.4)$ & $65(31.1)$ & $1.77(1.17,2.68)$ & \\
\hline Blocked nose & & & & $<.001$ \\
\hline Only with cold, rarely or never & $84(47.1)$ & $180(86.1)$ & 1.00 & \\
\hline Always or often & $94(52.8)$ & $29(13.9)$ & $6.95(4.25,11.34)$ & \\
\hline Variable & COME $n(\%)$ & Controls $n(\%)$ & $\mathrm{OR}(\mathrm{Cl})$ & $P$ value \\
\hline Snoring & & & & $<.001$ \\
\hline Never & $14(7.9)$ & 49 (23.6) & 1.00 & \\
\hline Seldom & $29(16.3)$ & $58(27.9)$ & $1.75(0.84,3.76)$ & \\
\hline Only with cold & $21(11.8)$ & $38(18.3)$ & $1.93(0.88,4.37)$ & \\
\hline Often & $46(25.8)$ & $37(17.8)$ & $4.35(2.13,9.32)$ & \\
\hline Always & $68(38.2)$ & $26(12.5)$ & $9.15(4.44,19.89)$ & \\
\hline Runny nose & & & & $<.001$ \\
\hline No & $11(6.2)$ & $35(16.7)$ & 1.00 & \\
\hline Only with cold & $85(47.8)$ & $126(60.3)$ & $2.15(1.06,4.64)$ & \\
\hline Yes - clear & $51(28.7)$ & $36(17.2)$ & $4.50(2.08,10.40)$ & \\
\hline Yes - purulent & $31(17.4)$ & $12(5.7)$ & $8.20(3.28,22.15)$ & \\
\hline Mouth breathing & & & & $<.001$ \\
\hline Never & $19(10.7)$ & $63(30.4)$ & 1.00 & \\
\hline Rarely & $39(22.0)$ & $44(21.3)$ & $2.94(1.52,5.83)$ & \\
\hline Only with cold & $28(15.8)$ & $52(25.1)$ & $1.79(0.90,3.59)$ & \\
\hline Often & $50(28.2)$ & $38(18.4)$ & $4.36(2.28,8.63)$ & \\
\hline Always & $41(23.2)$ & $10(4.8)$ & $13.59(5.95,33.63)$ & \\
\hline 4 or more colds in last 12 months & & & & $<.001$ \\
\hline No & $61(34.3)$ & $145(69.4)$ & 1.00 & \\
\hline Yes & $117(65.7)$ & $64(30.6)$ & $4.35(2.84,6.66)$ & \\
\hline Sibling tympanostomy tubes & & & & .002 \\
\hline No & $141(79.2)$ & $189(90.4)$ & 1.00 & \\
\hline Yes & $37(20.8)$ & $20(9.6)$ & $2.48(1.38,4.46)$ & \\
\hline Daycare hours per week & 174 & 208 & $1.02(1.00,1.04)$ & .03 \\
\hline Older siblings & & & & .07 \\
\hline No & $82(46.1)$ & 77 (36.8) & 1.00 & \\
\hline Yes & $96(53.9)$ & $132(63.2)$ & $0.68(0.45,1.03)$ & \\
\hline Maternal OM & & & & .02 \\
\hline No & $116(65.5)$ & $156(76.0)$ & 1.00 & \\
\hline Yes & $61(34.5)$ & $49(23.9)$ & $1.67(1.07,2.62)$ & \\
\hline Fully vaccinated & & & & .10 \\
\hline No & $16(9)$ & $30(14.4)$ & 1.00 & \\
\hline Yes & $162(91)$ & $178(85.6)$ & $1.71(0.90,3.25)$ & \\
\hline
\end{tabular}


pregnancy, mode of delivery, breastfeeding duration, formula feeding, colic, reflux, parental smoking, childhood use of vitamin $\mathrm{C}$, mouth breathing, full vaccination, probiotic use, wheezing, allergic rhinoconjunctivitis, runny nose, and maternal history of OM.

In the final multivariable model (Table 2), Asian ethnicity was inversely associated with COME as compared to European/Other ethnicity (OR: 0.20 [95\% CI: 0.07-0.53]). Deprivation was not associated. Long labour (OR: 2.59 [95\% CI: 1.03-6.79]), starting cow's

Table 2 Risk factors for COME in final multivariable model

\begin{tabular}{|c|c|c|}
\hline Variable & Adjusted OR (Cl) & $P$ value \\
\hline Age (per month) & $0.96(0.92,1.00)$ & .04 \\
\hline Sex & & .53 \\
\hline Female & 1.00 & \\
\hline Male & $1.18(0.70,1.99)$ & \\
\hline NZDep (per unit) & $1.06(0.96,1.17)$ & .27 \\
\hline Ethnicity & & .005 \\
\hline European/Other & 1.00 & \\
\hline Asian & $0.20(0.07,0.53)$ & \\
\hline Maori & $0.90(0.47,1.72)$ & \\
\hline Pacific Island & $1.33(0.58,3.04)$ & \\
\hline Long labour & & .04 \\
\hline No & 1.00 & \\
\hline Yes & $2.59(1.03,6.79)$ & \\
\hline Cow's milk start $<13$ months of age & & .03 \\
\hline No & 1.00 & \\
\hline Yes & $1.76(1.05,2.97)$ & \\
\hline Blocked nose in last 12 months & & $<.001$ \\
\hline Only with cold, rarely and never & 1.00 & \\
\hline Always and often & $4.38(2.37,8.28)$ & \\
\hline Snoring in last 3 months & & .02 \\
\hline Never & 1.00 & \\
\hline Seldom & $1.29(0.55,3.10)$ & \\
\hline Only with cold & $1.51(0.59,3.94)$ & \\
\hline Often & $2.45(1.04,5.96)$ & \\
\hline Always & $3.64(1.51,9.15)$ & \\
\hline 4 or more colds in last 12 months & & $<.001$ \\
\hline No & 1.00 & \\
\hline Yes & $2.67(1.59,4.53)$ & \\
\hline Sibling tympanostomy tubes & & .01 \\
\hline No & 1.00 & \\
\hline Yes & $2.68(1.22,6.02)$ & \\
\hline Daycare hours per week (per hour) & $1.03(1.00,1.05)$ & .02 \\
\hline Older siblings & & .03 \\
\hline No & 1.00 & \\
\hline Yes & $0.54(0.31,0.93)$ & \\
\hline
\end{tabular}

milk before 13 months of age (OR: 1.76 [95\% CI: 1.05-2.97]), and having a blocked nose (always or often, OR: 4.38 [95\% CI: 2.37-8.28]) were significant risk factors. Snoring was associated with COME when compared to never snoring (always, OR: 3.64 [95\% CI: 1.51-9.15]) or often (OR: 2.45 [95\% CI: 1.04-5.96]) Four or more colds in the last 12 months (OR: 2.67 [95\% CI: 1.59-4.53]), siblings with a history of TTP (OR: 2.68 [95\% CI: 1.22-6.02]), and number of hours per week at daycare (OR per hour: 1.03 [95\% CI: $1.00-1.05])$ were all risk factors, and having older siblings was inversely associated (OR: $0.54 \quad[95 \%$ CI: $0.31-0.93])$.

\section{Discussion}

To address the many inter-related factors associated with COME, we included a comprehensive set of variables in our regression analysis. In addition to well known risk factors such as frequent URI, daycare attendance, and sibling history of TTP, we also identified some respiratory risk factors that were independently associated with COME, notably nasal obstruction and snoring. Prenatal and perinatal events also appear to impact the risk of COME in preschoolers, including long labour and early introduction of cow's milk.

URI is a frequently observed risk factor [4, 12]. In animal models, bacteria in the nose are more likely to ascend to the middle ear if respiratory viruses are also present [13]. Our finding regarding URI may reflect viruses acting as a compounding risk factor through polymicrobial interactions with bacteria in the nose and nasopharynx.

Daycare attendance exposes children to infection that can lead to COME [12]. Children congregating at daycare increases the transfer of viruses, and the transmission of bacteria that may survive in a biofilm state in mucous secretions on toys and other surfaces [14]. Sibling TTP being a risk factor may reflect shared family environment including parental healthcare practices, awareness of COME, or exposure to the same pathogens. It may also indicate familial predisposition, which is a risk factor supported by a number of twin studies [15], however a history of maternal OM was not significant in the multivariable analysis.

Reports as to whether atopy and allergic rhinitis are risk factors for OME are mixed [4]. We did not find atopic diseases to be risk factors for COME. The discrepancy among studies could be explained by blocked nose or URI acting as confounders, as these conditions are associated with both allergic conditions and COME. We used a validated questionnaire for rhinoconjunctivitis, eczema and asthma, which may have improved our specificity in identifying allergic diseases. 
Frequent nasal obstruction in the last 12 months was reported in $53 \%$ of cases compared to $14 \%$ of controls, while frequent snoring in the last 3 months was found in $64 \%$ of cases versus $30 \%$ of controls. Nasal obstruction has been considered to be related to COME only via its associations with allergy and URI [16], however there is also evidence to support our finding that nasal obstruction and snoring can be associated with OM independently of allergy and colds [17-19]. Our observation that nasal obstruction was associated with COME independently of rhinitis, atopy, and URI raises the question of what other mechanism could be underlying this relationship. Given the importance of bacterial biofilms in the middle ear in causing COME [3], a possible explanation is that biofilms in the nose and nasopharynx act as a common factor for both chronic nasal obstruction and COME. In animal models biofilms can spread from the nose to the middle ear, leading to COME [13]. Nasal biofilms are associated with increased nasal resistance, a measure of nasal obstruction [20]. The otopathogen non-typable Haemophilus influenza requires anaerobic conditions to form biofilms [21], and may therefore be aided by nasal congestion. Although direct evidence that nasal and nasopharyngeal biofilms connect nasal obstruction to COME is lacking, adenoid hypertrophy in particular is a risk factor for nasal obstruction, snoring, and COME, with the preferred explanation being that adenoids can act as a reservoir for otopathogens [22, 23].

In addition to respiratory factors, we made several findings regarding socio-demographic factors, perinatal factors and feeding practices. Maori and Pacific Island children in NZ are more likely to fail preschool hearing tests [24]. The prevalence of OME in 2 year old Pacific Island children has been measured at $25.4 \%$, however chronicity and other ethnicities were not studied, and subjects were recruited from a less affluent area of Auckland [18]. We did not observe Maori or Pacific Island ethnicities to be risk factors for COME. If a correlation exists, it may be concealed by these families being less likely to attend primary care practices for COME, as our subjects are limited to those referred for surgery.

Asian ethnicity was inversely associated with COME. It is also inversely correlated with a diagnosis of AOM in the US [25]. A longitudinal study could determine whether this reflects a lower likelihood of referral/attendance for TTP surgery, genetic propensity, or cultural differences such as diet, housing, or hygiene practices.

Low SES is sometimes linked to OM [4]. In NZ, deprivation is associated with infectious diseases [26], surgical interventions for OM [27], and infection with the otopathogen Staphylococcus aureus [28]. However, we did not find deprivation to be associated with COME. Crowding and tobacco smoke exposure were also not identified as risk factors, in contrast to some previous studies $[29,30]$. It appears that the presence of COME is better predicted by other potentially related factors in our subjects.

Having older siblings was inversely correlated with COME. Previous research has found this to be a risk factor that declines with age, no longer being associated by 3 years of age [12]. Exposure to commensal bacteria from older siblings may help to protect children from infections and allergic manifestations [31].

Long labour was associated with COME. Prolongation of labour is the most common cause of maternal fever during labour, and is also associated with instrument use, emergency Caesarean section deliveries, and admission to neonatal care units [32-34]. In cases of maternal fever, prophylactic antibiotics are often administered to mother and newborn, which may affect the infant's microbiome and thereby decrease their resistance to colonization with pathogens [31, 34].

Longer duration of breastfeeding is sometimes reported as a protective factor against OM, and early introduction of infant formula or cow's milk is sometimes found to be a risk factor [35]. The introduction of cow's milk before 13 months of age was a risk factor for COME. Cow's milk is not recommended until after 12 months of age, because its composition is significantly different to breast milk and infant formula, and its use can lead to iron deficiency [36, 37]. Another consideration is cow's milk protein allergy, which is associated with TTP [38]. We did not find infant formula to be a risk factor, even though it usually contains cow's milk. This could be due to the differences in its content, or the use of hypoallergenic and dairy-free varieties. Infant consumption of cow's milk also supports a different microbiome composition [39], which could promote pathogen colonization leading to COME.

A recent systematic review concluded that children with COME have a high prevalence of reflux, and suggested that aspiration of pepsin into the airways may result in an inflammatory response in the middle ear cavity [40]. Frequent reflux and colic were not significant in our final model and may only be related to COME via other risk factors.

Study limitations need to be considered. The cases were referred for surgery, so they may not represent all preschool children with COME. Retrospective case-control designs have a potential for selection bias and recall bias. Selection bias was mitigated by recruiting controls from practices that had recently referred preschoolers for surgery and by having a high participation rate. Differential recall bias was mitigated with the use of a standardized questionnaire using validated questions where available. While NZDep is a useful indicator of deprivation, it reflects data from a small area of houses 
rather than specific households. A major strength of the study is that an otorhinolaryngologist confirmed disease presence at surgery, which is preferable to relying on medical history or tympanometry alone. Furthermore, a comprehensive range of risk factors were explored and the sample size was relatively large, allowing us to have confidence in these findings.

\section{Conclusion}

Our results support well-established risk factors for COME relating to exposure to infection, specifically URI, daycare attendance, and sibling TTP.

There is growing interest in how respiratory microbiota may support the immune system against conditions such as COME. More investigation is required to confirm whether our results regarding older siblings, prolonged labour (with associated antibiotic use), and the timing of cow's milk introduction reflect effects on the commensal microbiota.

We postulate that biofilms in the nose and nasopharynx link nasal obstruction, snoring, and COME. The child's nose or nasopharynx is first colonized by otopathogenic bacteria that form biofilms. The resulting chronic inflammation may cause nasal obstruction and snoring, but fails to fully suppress the biofilm infection. The otopathogens pass up the Eustachian tube to the middle ear, a risk that is compounded by viral infection, and form biofilms again in the middle ear. This may produce chronic inflammation in the middle ear, i.e. COME. Research on the association between bacterial biofilms in the nose and nasopharynx, nasal obstruction, and COME is required to test this hypothesis.

\section{Abbreviations \\ AOM: Acute otitis media; BMI: Body mass index; COME: Chronic otitis media with effusion; ISAAC: The International Study of Asthma and Allergy in Children; NZ: New Zealand; NZDep: New Zealand Deprivation Index; OM: Otitis media; OME: Otitis media with effusion; SD: Standard deviation; TTP: Tympanostomy tube placement; URI: Upper respiratory infection}

\section{Acknowledgments}

We would like to thank Ann Paddy, DHSc, who administered the questionnaires and performed part of the physical examinations for the children involved in the study. Peter Reed, DPhil, helped with the statistical analysis. We would like to acknowledge the staff at Waitakere and North Shore Hospital, Bede Saldanha and Denise Burdett for going above and beyond reception support, and especially ear nurse specialist Barbara Middleton. Finally, a thank you to the families and their general practitioners whose help and support made the study possible. Edwin Mitchell and John Thompson were supported by Cure Kids.

\section{Funding}

The Oticon Foundation, Starship Foundation, Brian Johns Fellowship Trust, Deafness Research Foundation, and Cure Kids.

\section{Availability of data and materials}

Data is available on request from the author.

\section{Authors' contributions}

REW designed the study, conducted all data collection, data analysis and interpretation, drafted the initial manuscript, and approved the final manuscript as submitted. JB assisted in the study design, supervised the data analysis and interpretation, reviewed and revised the manuscript, and approved the final manuscript as submitted. DF assisted in the study design, was involved in data collection, and approved the final manuscript as submitted. JMDT assisted in the study design, was involved in the data analysis, and approved the final manuscript as submitted. EAM designed the study, supervised the data analysis and interpretation, reviewed and revised the manuscript, and approved the final manuscript as submitted.

\section{Competing interests}

The authors declare that they have no competing interests.

\section{Consent for publication}

Not applicable.

\section{Ethical approval and consent to participate}

The parents or legal guardians were informed of the nature of the study and provided written consent. The study was approved by the Northern $X$ Regional Ethics Committee (reference NTX/11/EXP/027).

\section{Author details}

${ }^{1}$ Department of Paediatrics: Child and Youth Health, The University of Auckland, Private Bag 92019, Auckland 1142, New Zealand. ${ }^{2}$ Division of Otolaryngology-Head and Neck Surgery, Counties-Manukau District Health Board, Manukau SuperClinic ${ }^{\text {MM }}$, PO Box 98743, Manukau City, Auckland 2241, New Zealand

Received: 2 June 2016 Accepted: 21 December 2016

Published online: 06 January 2017

\section{References}

1. Bakaletz LO. Bacterial biofilms in otitis media: evidence and relevance. Pediatr Infect Dis J. 2007;26(10):S17-9

2. Bennett KE, Haggard MP, Silva PA, Stewart IA. Behaviour and developmental effects of otitis media with effusion into the teens. Arch Dis Child. 2001; 85(2):91-5.

3. Hall-Stoodley L, Hu FZ, Gieseke A, Nistico L, Nguyen D, Hayes J, Forbes M, Greenberg DP, Dice B, Burrows A, et al. Direct detection of bacterial biofilms on the middle-ear mucosa of children with chronic otitis media. JAMA. 2006;296(2):202-11.

4. Hoffman HJ, Daly KA, Bainbridge KE, Casselbrant ML, Homøe P, Kvestad E, Kvaerner KJ, Vernacchio L. Panel 1: epidemiology, natural history, and risk factors. Otolaryngol Head Neck Surg. 2013;148(4 suppl):E1-E25.

5. Waitemata District Health Board. Annual Report 2012/2013. http://www. waitematadhb.govt.nz/assets/Documents/annual-Reports/Annual-Report-20122013-Ir.pdf.

6. Ministry of Health. Ethnicity data protocols for the health and disability sector. 2004. http://www.health.govt.nz/system/files/documents/publications/ ethnicitydataprotocols.pdf.

7. Atkinson J, Salmond C, Crampton P. NZDep2013 index of deprivation. 2014.

8. ASCIA. Skin prick testing for the diagnosis of allergic disease: A manual for practitioners. 2009. http://www.allergy.org.au/images/stories/ascia_spt_ manual 2009.pdf.

9. Gardosi J, Francis A. Customised Weight Centile Calculator. Gestation Network. 2013. http://www.gestation.net/.

10. Cole TJ, Freeman JV, Preece MA. Body mass index reference curves for the UK, 1990. Arch Dis Child. 1995;73:25-9.

11. Plunket. Glue ear. Royal New Zealand Plunket Society Incorporated. http:// www.plunket.org.nz/your-child/illness/health-conditions/glue-ear. Accessed 13 May 2016.

12. Dewey C, Midgeley E, Maw R. The relationship between otitis media with effusion and contact with other children in a British cohort studied from 8 months to 3 1/2 years. Int J Pediatr Otorhinolaryngol. 2000;55(1):33-45.

13. Wren JT, Blevins LK, Pang B, King LB, Perez AC, Murrah KA, Reimche $J$, Alexander-Miller MA, Swords WE. Influenza a virus alters pneumococcal nasal colonization and middle ear infection independently of phase variation. Infect Immun. 2014;82(11):4802-12.

14. Blanchette KA, Orihuela CJ. Future perspective on host-pathogen interactions during bacterial biofilm formation within the nasopharynx. Future Microbiol. 2012;7(2):227-39.

15. Daly KA, Hoffman HJ, Kvaerner KJ, Kvestad E, Casselbrant ML, Homoe P, Rovers MM. Epidemiology, natural history, and risk factors: panel report from 
the ninth international research conference on otitis media. Int J Pediatr Otorhinolaryngol. 2010;74(3):231-40.

16. Fireman P. Otitis media and eustachian tube dysfunction: connection to allergic rhinitis. J Allergy Clin Immunol. 1997;99(2):S787-797.

17. Lok W, Anteunis $L$, Meesters C, Chenault MN, Haggard MP. Risk factors for failing the hearing screen due to otitis media in Dutch infants. Eur Arch Otorhinolaryngol. 2012;269(12):2485-96.

18. Paterson JE, Carter S, Wallace J, Ahmad Z, Garrett N, Silva PA. Pacific islands families study: risk factors associated with otitis media with effusion among pacific 2-year-old children. Int J Pediatr Otorhinolaryngol. 2007;71(7):1047-54

19. Souter MA, Mills NA, Mahadevan M, Douglas G, Ellwood PE, Asher MI, Clayton TO, Douglas RG. The prevalence of atopic symptoms in children with otitis media with effusion. Otolaryngol Head Neck Surg. 2009; 141(1):104-7.

20. Gelardi M, Passalacqua G, Fiorella M, Quaranta N. Assessment of biofilm by nasal cytology in different forms of rhinitis and its functional correlations. Eur Ann Allergy Clin Immunol. 2013;45(1):25-9.

21. Osgood R, Salamone F, Diaz A, Casey JR, Bajorski P, Pichichero ME. Effect of $\mathrm{pH}$ and oxygen on biofilm formation in acute otitis media associated $\mathrm{NTHi}$ clinical isolates. Laryngoscope. 2015;125(9):2204-8.

22. Wang DY, Bernheim N, Kaufman L, Clement P. Assessment of adenoid size in children by fibreoptic examination. Clin Otolaryngol Allied Sci. 1997; 22(2):172-7.

23. Post JC, Hiller NL, Nistico L, Stoodley P, Ehrlich G. The role of biofilms in otolaryngologic infections: update 2007. Curr Opin Otolaryngol Head Neck Surg. 2007;15:347-51.

24. Cook L. Screening programmes for the detection of otitis media with effusion and conductive hearing loss in pre-school and new entrant school children, vol. 3. New Zealand Health Technology Assessment Clearing House: Christchurch; 1998. p. 1-61.

25. Vernacchio L, Lesko SM, Vezina RM, Corwin MJ, Hunt CE, Hoffman HJ, Mitchell AA. Racial/ethnic disparities in the diagnosis of otitis media in infancy. Int J Pediatr Otorhinolaryngol. 2004;68(6):795-804.

26. Baker MG, Barnard LT, Kvalsvig A, Verrall A, Zhang J, Keall M, Wilson N, Wall T, Howden-Chapman P. Increasing incidence of serious infectious diseases and inequalities in New Zealand: a national epidemiological study. Lancet. 2012;379(9821):1112-9.

27. Milne RJ, Vander Hoorn S. Burden and cost of hospital admissions for vaccine-preventable paediatric pneumococcal disease and non-typable Haemophilus influenzae otitis media in New Zealand. Appl Health Econ Health Policy. 2010;8(5):281-300.

28. Williamson DA, Lim A, Thomas MG, Baker MG, Roberts SA, Fraser JD, Ritchie SR. Incidence, trends and demographics of staphylococcus aureus infections in Auckland, New Zealand, 2001-2011. BMC Infect Dis. 2013;13(1):569.

29. Jones LL, Hassanien A, Cook DG, Britton J, Leonardi-Bee J. Parental smoking and the risk of middle ear disease in children: a systematic review and meta-analysis. Arch Pediatr Adolesc Med. 2012;166(1):18-27.

30. Bowie C, Pearson AL, Campbell M, Barnett R. Household crowding associated with childhood otitis media hospitalisations in New Zealand. Aust N Z J Public Health. 2014;38(3):211-5.

31. Penders J, Thijs C, Vink C, Stelma FF, Snijders B, Kummeling I, van den Brandt PA, Stobberingh EE. Factors influencing the composition of the intestinal microbiota in early infancy. Pediatrics. 2006;118(2):511-21.

32. Nystedt A, Hildingsson I. Diverse definitions of prolonged labour and its consequences with sometimes subsequent inappropriate treatment. BMC Pregnancy Childbirth. 2014;14(1):233.

33. Maghoma J, Buchmann E. Maternal and fetal risks associated with prolonged latent phase of labour. J Obstet Gynaecol. 2002;22(1):16-9.

34. Maayan-Metzger A, Mazkereth R, Shani A, Kuint J. Risk factors for maternal intrapartum fever and short-term neonatal outcome. Fetal Pediatr Pathol. 2006;25(3):169-77.

35. MCNiel ME, Labbok MH, Abrahams SW. What are the risks associated with formula feeding? a re-analysis and review. Birth. 2010;37(1):50-8.

36. Agostoni C, Decsi T, Fewtrell M, Goulet O, Kolacek S, Koletzko B, Michaelsen KF, Moreno L, Puntis J, Rigo J. Complementary feeding: a commentary by the ESPGHAN committee on nutrition. J Pediatr Gastroenterol Nutr. 2008;46(1):99-110.

37. Brennan-Jones CG, Whitehouse AJ, Park J, Hegarty M, Jacques A, Eikelboom $\mathrm{RH}$, Swanepoel DW, White JD, Jamieson SE. Prevalence and risk factors for parent-reported recurrent otitis media during early childhood in the western Australian pregnancy cohort (Raine) study. J Paediatr Child Health. 2015;51(4):403-9.

38. Gibbons TE, Patil SN, Frem JC, Smith C, Wakwe J, Swearingen CJ. Non-lgE-mediated cow milk allergy is linked to early childhood clusters of commonly seen illnesses a pilot study. Clin Pediatr. 2012;51(4):337-44.

39. Nielsen S, Nielsen D, Lauritzen L, Jakobsen M, Michaelsen K. Impact of diet on the intestinal microbiota in 10-month-old infants. PediatrGastroenterol, Hepatol Nutr. 2007:44(5):613.

40. Miura MS, Mascaro M, Rosenfeld RM. Association between otitis media and gastroesophageal reflux a systematic review. Otolaryngol Head Neck Surg. 2012;146(3):345-52.

\section{Submit your next manuscript to BioMed Central and we will help you at every step:}

- We accept pre-submission inquiries

- Our selector tool helps you to find the most relevant journal

- We provide round the clock customer support

- Convenient online submission

- Thorough peer review

- Inclusion in PubMed and all major indexing services

- Maximum visibility for your research

Submit your manuscript at www.biomedcentral.com/submit
) Biomed Central 